\title{
Influence of Devolution Monitoring and Evaluation on Service Delivery in
} Garissa County Government

\author{
Issa Mohamed Hussein ${ }^{1}$, Prof. David Minja ${ }^{2}$ \\ ${ }^{1}$ Correspondent Author, Department of Public Policy and Administration, Kenyatta University, \\ Kenya \\ ${ }^{2}$ Department of Public Policy and Administration, Kenyatta University, Kenya
}

\section{ABSTRACT}

Service delivery in the county government, just as is in the national government, has been termed as not satisfactory. Some of the ways seconded to improve the situation is introduction of monitoring and evaluation. Monitoring and Evaluation system provides the necessary feedback for economic development and policy interventions. However, this area has not received the much-needed attention especially in the county level. In order to accurately and timely track the development progress made in Kenya and the 47 counties in particular, there is need for an efficient M\&E system. The absence of this framework limits effective public service delivery thus constraining the acceleration of economic development in Kenya and therefore impacts negatively on the overall welfare of the citizens. To find out the effect of monitoring and evaluation on service delivery in the devolved system, this study is timely so as to make policy recommendations for improvement. This study specifically aimed to establish the effect of performance monitoring on service delivery in a devolved system, to determine the effect of measuring results on service delivery in a devolved system, to find out the effect of reporting and learning on service delivery in a devolved system and to determine the effect of monitoring and evaluation systems on service delivery in a devolved system. The study was guided by the Programme theory of Evaluation, Resource Dependency Theory and the Stakeholder Theory. A descriptive survey research design was adopted for the study. The population of the study was the main committees involved in discussing reports relating to monitoring and evaluation of CIDP preparation and implementation progress at county level. A census was conducted on this population. Data was collected through structured questionnaires of the Likert format. After collection, both descriptive and inferential statistics was established through SPSS software. The study found out that performance monitoring had a positive influence in service delivery at Garissa County Government. Measuring results significantly influenced service delivery at Garissa county government. Reporting and learning had a significant influence on service delivery at Garissa county government. Monitoring and evaluation systems significantly influenced service delivery at Garissa county government. The study concludes that the county government of Garissa performed evaluation of cost performance. The county government evaluated whether projects in the county were of high-quality performance. The county government conducted surveys to establish the durability of projects. The county government established the sustainability of Projects before implementation. Garissa county government established the frequency of reporting monitoring and evaluation information. The county government of Garissa had up to date routine monitoring systems for effective $M$ \& E process. The study recommends that the county government of Garissa ought to performed evaluation of cost performance. The county government ought to conduct surveys to establish the durability of 
projects. The county government ought to establish the sustainability of Projects before implementation. The county government ought to establish flexible feedback mechanisms for monitoring and evaluation results. Garissa county government ought to establish the frequency of reporting monitoring and evaluation information. The county government of Garissa ought to have an up to date routine monitoring systems for effective $M \&$ E process.

Key Words: Devolution, Monitoring and Evaluation, Service Delivery

DOI: 10.7176/ijcab.v3iII.25, URN urn:nbn:de:0000ijcab.v3iII.257

\section{Cite this Article:}

Hussein, I., \& Minja, D. (2019). Influence of Devolution Monitoring and Evaluation on Service Delivery in Garissa County Government. International Journal of Current Aspects, 3(II), 305-318. http://journals.ijcab.org/journals/index.php/ijcab/article/view/25

\section{INTRODUCTION}

Monitoring and Evaluation has been a key performance management tool for planning, decision making and economic policy management. Mackay, 2007 asserts that most governments in the world are working towards entrenching Monitoring and Evaluation (M\&E) in their economic governance system. The success of projects plays a key role in achieving organizational growth and development. Most project managers appreciate that monitoring and evaluation (M\&E) of projects is important if the project objectives and success is to be achieved (Kahilu, 2010). The devolved system of governance resulted in County Governments assuming substantial development, service delivery and financial accountability responsibilities. The legal mechanisms spelt out in the Constitution of Kenya, have necessitated the development of Monitoring and Evaluation (M\&E) systems for county governments. The Constitution requires adherence to principles of good governance and transparency in the conduct and management of public programmes/projects. For devolution to succeed in Kenya, county and national governments are united, in the recognition that performance monitoring and evaluation are pivotal development and service delivery tools for leaders at all levels. Thus, the focus of both county and national governments is increasingly on development results and how they can best be measured. The county governments have therefore developed monitoring and evaluation systems which is a set of organizational structures, management processes, standards, strategies, plans, indicators, information systems, reporting lines and accountability relationships which enables national and provincial departments, municipalities and other institutions to discharge their M\&E functions effectively. In addition to these formal managerial elements are the organizational culture, capacity and other enabling conditions which would determine whether the feedback from the M\&E function influence the organization's decision-making, learning and service delivery (Mugo, 2014).

Key to monitoring and evaluation of devolution is the collection of information on changes in the political, legal, and institutional frameworks in which the process is set. This requires collecting information on enactment and enforcement of legislation and procedures that define new institutions, divide responsibilities, and hold stakeholders legally accountable; and on the policy, planning, and regulatory bodies and processes. Few quantitative indicators are available for these political, institutional and legal factors, as much of the requisite information focuses on nonquantifiable issues - such as which level of government has responsibility for which function or on the presence of key inputs - such as the existence of government documents outlining the 
responsibilities of the different levels of government. Many indicators are dichotomous "yes/no" indicators. Systematic collection of information, analysis and reporting of results therefore appear critical to the devolution process. $\mathrm{M} \& \mathrm{E}$ is needed at the local level to inform residents and encourage public participation. At the central level $M \& E$ is needed to monitor and supervise local activities and to provide information for policy development and other institutional responses. $\mathrm{M} \& \mathrm{E}$ is particularly relevant in a context of trial and error and stand-alone initiatives undertaken by disparate actors (Roselyne, 2016). According to Leuzzi (2013), the improvement of local governance in terms of efficiency, effectiveness and accountability is increasingly recognized as a primary vehicle for influencing governance at all levels: central, regional and international. This also extends to civil society and the private sector. Local governance is argued to provide a direct mechanism for people to participate in government, forming a framework that enables the interests of communities to be represented in decision making structures. Scholars argue that improvement of governance at the local level is the most effective means of building this relationship, enabling human and financial resources to be directly and effectively mobilized in support of improved governance at all levels. To this end many governments and cooperation agencies have devoted resources to devolution. The anticipation is that devolution would lead to improvements in service delivery and local accountability.

M\&E has been a key performance management tool for planning, decision making and economic policy management. Mackay (2007) asserts that most governments in the world are working towards entrenching M\&E in their economic governance system. As cited by Kibua and Mwabu, (2008), the DFRD policy did not succeed because of the absence of an appropriate legal framework to facilitate decision making and to mobilize resources. Absence of monitoring and evaluation is also cited by Republic of Kenya (2008). The new devolved structures of county governments and the rising fiscal devolution with respect to development policies, programs and projects in Kenya, there is dire need therefore for an effective national wide M\&E framework in Kenya. Further, with decentralization of accountability in light of the new governance structure in Kenya, line managers have become more responsible for non-core functions, such as human resource development and equity. The key strategic challenge is to increase public service effectiveness, so that the entire government achieves her desired policy outcomes and strategic objectives. This makes national wide $M \& E$ in Kenya critically important. The Ministry of Devolution and Planning (MoDP) and the Council of Governors (CoG) are committed to developing as centers of excellence in performance management for public service delivery. By coordinating their efforts, they intend to accelerate progress in the counties to achieve a high quality of life for all Kenyans. The County Integrated Monitoring and Evaluation System (CIMES)was developed to create a strong feedback mechanism that regularly provide county residents with good quality and timely monitoring and evaluation (M\&E) information regarding implementation progress of flagship development projects and programmes. It is against this backdrop that the study seeks to establish the role of monitoring and evaluation in devolved system service delivery using a case study of Garissa county government.

Garissa County is in the former North Eastern Province of Kenya. According to Kenya National Bureau of Statistics (2009), Garissa County has a total population of 623,060. A male population of 334,939 and a female population of 288,121 . Livestock production is a significant part of the county's economy. Livestock is a crucial source of financial capital for the rural poor. The arid and semi-arid lands are home to nearly $70 \%$ of the national herd with an estimated value of Kenya shillings 70 billion. For many, it is the only form of savings available. Therefore, its 
efficient production and marketing is essential for sustaining pastoral livelihoods. The existing Garissa livestock market in Garissa town, Garissa County covers a total area of approximately 10 acres. It provides a range of employment and income-earning opportunities to the resident of not only Garissa County but the entire northern region. The dry and arid landscape could be exploited to offer tourism packages that encompass camel-back expeditions and camping activities. This compliments attractions such as the bour-algy Giraffe Sanctuary and other wildlife that contribute to the county's tourism industry. Financial and resource monitoring in Garissa County has been below expectations with the Senator and the County Assembly Members getting compromised to perform their oversight role. This has retarded the realization of devolution fruits among the residents of the county precipitated by poor service delivery. This study seeks to establish the effect of monitoring and evaluation on service delivery in Garissa County.

\section{STATEMENT OF THE PROBLEM}

Service delivery in the public sector globally and specifically in Kenya has been below expectations due to bureaucracy, poor human resource management and weak monitoring and evaluation systems for economic development and policy interventions. County governments have followed suit despite their recent formation. County governments in Kenya have been marred with rampant corruption, misappropriation of resources, limited accountability to the taxpayers and poor service delivery. Resource monitoring and evaluation is therefore significant in improving service delivery among the devolved units in Kenya. In order to accurately and timely track the development progress made in Kenya and the 47 counties in particular, there is need for an efficient M\&E system. The absence of this framework limits effective public service delivery thus constraining the acceleration of economic development in Kenya and therefore impacts negatively on the overall welfare of the citizens. The factors influencing the implementation of $\mathrm{M} \& \mathrm{E}$ of development projects in Kenya therefore need to be timely established to guide the implementation of M\&E function and policy development in Kenya.

At county level, the governments are beginning to set up units/departments responsible for developing crucial systems needed for M\&E, performance management, and statistical data collection. At this initial stage, the counties face a number of challenges relating to the development and use of M\&E systems. The draft M\&E Policy and draft M\&E Framework, which are crucial to formalization of the $M \& E$ structures that are being established, have not yet been finalized in some of the counties. M\&E units are not yet operational in some counties, and where they exist, they may not have the required skills and capacity. In counties that have established M\&E units, their M\&E reports are not well coordinated resulting in the use of different M\&E definitions and concepts. Despite the interventions made to strengthen M\&E of public development programmes, the following challenges are still being experienced; weak $M \& E$ culture, weak $M \& E$ reporting structures and multiple and uncoordinated monitoring and evaluation systems within and among institutions, weak institutional, managerial and technical capacities, untimely, rarely analyzed or disseminated data and low utilization of data/information and weak legal framework. In county governments M\&E systems, there are many challenges. Some Delivery Agreements are too long and detailed with too many indicators and not strategic, management culture of public service, lack of focus on measurement of impact - some quarterly reports focus exclusively on progress with activities and do not cover indicators of impact. 
In County government of Garissa, there is lack of culture of continuous improvement and lack of culture of coordination and information management systems to produce required data not fully in place in many departments, and required data sometimes not available. Evidence suggests that in county governments, there is tendency to report on outcomes for compliance reasons, rather than to use reports to analyses progress against key indicators and identify ways of doing things better, to improve impact. Some reports only focus on the positive and lack of synergy between reported progress and public experience of the quality of service. Most studies done in Kenya including Nyabuto (2010), Rogito (2010) and Mogaka (2010) focuses on specific projects or specific districts and therefore makes it difficult to generalize the results on the counties. Equally, these studies do not look at a wider cross section of projects being funded by county governments and this study attempts to fill the gap by identifying the role of monitoring and evaluation in devolved system service delivery by Garissa county government. The study therefore sought to establish the role of monitoring and evaluation on service delivery in the devolved system

\section{OBJECTIVES OF THE STUDY}

i. To establish the effect of performance monitoring on service delivery in a devolved system

ii. To determine the effect of measuring results on service delivery in a devolved system

iii. To find out the effect of reporting and learning on service delivery in a devolved system

iv. To determine the effect of monitoring and evaluation systems on service delivery in a devolved system

\section{THEORETICAL FRAMEWORK}

This part of the study contains the theories upon which the study was hinged on. The study was anchored on the Programme theory of Evaluation, Resource Dependency Theory and the Stakeholder Theory. The theories are discussed in the sub sections that follow.

\subsection{Programme Theory of Evaluation}

Program Theory guides an evaluation by identifying key programme elements and articulating how these elements are expected to relate to each other. Data collection plans are then made within the framework in order to measure the extent and nature of each element's occurrence. Once collected, the data are analyzed within the framework. First, data that have been collected by different methods or from different sources on the same programme element are triangulated, Denzin (2011) presented a model that calls for describing the intended antecedents (whatever needs to be before a programme is operational) transactions (activities and outputs), and outcomes of a programme. The data on the programme in operation are compared to what was intended and to what the standards are for that kind of programme. Program theory is defined in evaluation practice today as the construction of a plausible and sensible model of how a program is supposed to work, or a set of propositions regarding what goes on in the black box during the transformation on input to output, that is, how a bad situation is transformed into a better one through treatment inputs (Lipsey, 1993). It is also looked at as the process through which program components are presumed to affect outcomes. Rossi (2004 describes program theory as consisting of the organizational plan which deals with how to garner, configure, and deploy resources, and how to organize program activities so that the intended service system is developed and maintained. The theory also deals with the service utilization plan which looks at 
how the intended target population receives the intended amount of the intended intervention through interaction with the programs service delivery system. Finally, it looks at how the intended intervention for the specified target population brings about the desired social benefits (impacts). Rogers, as cited by Uitto (2000) identifies advantages of the theory-based framework to monitoring and evaluation to include being able to attribute projects outcomes to specific projects or activities and identify unanticipated and undesired programme or project consequences. Theory based evaluations enable the evaluator to tell why and how the programme is working.

\subsection{Stakeholder Theory}

This study would borrow from the stakeholder theory. Stakeholder's theory argues that every legitimate person or group participating in the activities of a firm or organization, do so obtain benefits, and that the priority of the interest of all legitimate stakeholders is not self-evident (Patton, 2008). Stakeholder Theory pays equal credence to both internal and external stakeholders; employees, managers and owners as well as financiers, customers, suppliers, governments, community and special interest groups. The managerial importance of stakeholder management has been accentuated in various studies (Ramabodu \& Verster, 2010) that demonstrate that just treatment of stakeholders is related to thelong term survival of the organization. This theory emphasizes the significance of the relationship between the top management staff with the stakeholders. Specifically, managers should understand the success of the projects can be influenced greatly by the participation of various stakeholders. These stakeholders would participate depending on the relationship they foster with the top management and not junior workers acting on their behalf. M\&E involves stakeholders including local people in deciding how progress should be measured, in defining criteria for success and in determining how results should be acted upon (Guijt \& Gaventa, 2011). PME strives to be an internal learning process that enables people to reflect on past experience, examine present realities, revisit objectives and define future strategies by recognizing differential stakeholders' priorities and negotiating their diverse claims and interests (Estrella et al., 2010). In these processes the local people are involved in developing indicators to measure change, in collecting and analyzing the data, and making a decision as to how to adjust the activities.

The use of stakeholders in assessments is not undisputed, however. Some authors question how far stakeholders can be trusted to correctly assess the complex environment in which they are immersed, to reach consensus, and how tendencies towards self-interest can be tackled (Hacking and Guthrie 2006). A general problem concerning stakeholder participation processes is that these tend to quickly lead to a 'unique' solution to a complex problem that is difficult to scale-up or apply in other contexts. By definition, given the subjective and normative nature of sustainability issues, the problem itself and its boundaries are unclear (Van de Kerkhof and Wieczorek 2005). The generated outputs are only applicable to that specific moment in time, to the specific region and its characteristics and to the stakeholder groups that were involved. Applied to participatory monitoring, these issues raise questions in how far the participation of stakeholders in monitoring leads to differences in the results of participatory monitoring? To answer this question, a systematic framework is needed to evaluate the participation of stakeholders in monitoring in the first place. The stakeholders' theory suggests that a company's stakeholders include people like employees, customers, community members, competitors, vendors, contractors, and shareholders. The organization acts in trust, good faith and in the interest of the stakeholders. County governments were meant to bring services closer to the 
people and therefore need to be accountable and serve the interests of the citizenry. This theory indicates that county government's resource use should be geared towards betterment of the welfare of the taxpayers or locals which monitoring seeks to ensure.

\subsection{Resource Dependency Theory}

This study would also be pegged on the resource dependency theory which was postulated by Pfeiffer and Salancil, (1978). The theory postulates that organizations rely on resources which are obtained from their environment and that the survival of such organizations depends greatly on their ability to acquire and utilize the resources. Pfeiffer and Salancil (1978) states that, the need for resources and an outlet for finished products and services, have forced organizations to depend on their environment. The environment in return has exerted influence on the entities that depend on it. Hatch (2013) further highlights that such entities cannot survive if they are not guaranteed the continuous supply of the critical resources which can be done by retaining multiple sources of supply, engaging in vertical integration with the suppliers, creating joint ventures, and horizontal integration with competitors. This argument is reinforced further by the institutional organizational theory which postulates that an organization can have all the resources in form of raw materials, labor and capital from the environment but if it is not accepted by the same society, it cannot succeed. Furthermore, according to the input-output model, an organization's survival depends not only on the availability of resources in the form of raw, materials, labor and capital equipment but also social legitimacy for it to thrive (Nguu, 2003).

\section{CONCEPTUAL FRAMEWORK}

A conceptual framework is a set of broad ideas and principles taken from relevant fields of enquiry and used to structure a subsequent presentation (Kombo \& Tromp, 2009). A conceptual framework is a research tool intended to assist a researcher to develop awareness and understanding of the situation under scrutiny and to communicate it. When clearly articulated, a conceptual framework has potential usefulness as a tool to assist a researcher to make meaning of subsequent findings. It forms part of the agenda to be scrutinized, tested, reviewed and reformed as a result of investigation and it explains the possible connections between the variables (Smyth, 2004). The conceptual framework illustrates the dependent and independent variables. The independent variables include performance monitoring, measuring results, reporting and learning and monitoring and evaluation systems. The dependent variable is the devolved system service delivery. 


\section{Performance Monitoring}

- Cost performance evaluation

- Time performance evaluation

- Quality performance delivery

\begin{tabular}{ll|}
\hline Measuring Results \\
- & Compatibility test \\
- & Feasibility tests \\
- & Projects Sustainability \\
& establishment
\end{tabular}

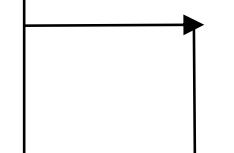

\section{Reporting and Learning \\ - Mode of reporting \\ - Frequency of reports \\ - Feedback mechanisms}

\section{Monitoring and Evaluation Systems \\ - Appraisal systems \\ - Routine monitoring systems \\ - Databases}

\section{Figure 1: Conceptual Framework}

\section{RESEARCH METHODOLOGY}

This study used descriptive survey research design to establish the role of monitoring and evaluation on devolved service delivery in Garissa County. The descriptive survey method was used by the researcher as the appropriate method for the research at hand because it is the most appropriate in collecting data about the characteristics of a large population in terms of being cost effective and within the constraints of time available. Moreover, the questionnaire was employed as the main tool for data collection (Harrison \&Clock, 2004). The population of the study was the main committees involved in discussing reports relating to monitoring and evaluation of CIDP preparation and implementation progress at county level. The committees include: County M\&E Committee (12), Technical Oversight Committees (ToC) (8) and M\&E Unit consisting of Director of County Economic Planning Department (1), County M\&E Officer (1), M\&E Officers (8) under Director of Economic Planning, County ward administrators (30) 
and villages administrators (30), therefore the target population comprised of 92 respondents. The study adopted a census instead of carrying sampling. Census technique was more suitable for the study since the population of 92 is small.

The study collected data using self-administered questionnaires from the study respondents; the questionnaire was formulated using Likert scale type of questions rating from very low extent to very high extent. This enabled the researcher to study the employee's perception on the role of M\&E on devolved service delivery. After successful data collection, the collected data was organized for processing. This involved; coding the responses, tabulating the data and performing several statistical computations. Using SPSS statistical software, the study employed both descriptive and inferential statistics to analyse data collected and organized. The analysis procedure was uniform in all study objectives where descriptive and inferential statistics was used. Descriptive statistics; Frequencies, Percentages, Mean and Standard Deviation was calculated on the independent variables to summarize and classifying the data collected into meaningful form for easy interpretation. Inferential statistics; Pearson Correlation and Regression was used to test the relationship between the independent and the dependent variable.

\section{DATA ANALYSIS}

The study carried out correlation analysis to establish the relationship between devolution monitoring and evaluation on service delivery in Garissa County Government. The findings are as shown in Table 1.

Table 1: Correlation Analysis

\begin{tabular}{|c|c|c|c|c|c|c|}
\hline & & $\begin{array}{l}\text { Service } \\
\text { Delivery }\end{array}$ & $\begin{array}{c}\text { Performance } \\
\text { Monitoring }\end{array}$ & $\begin{array}{l}\text { Measurin } \\
\text { g Results }\end{array}$ & $\begin{array}{l}\text { Reporting } \\
\text { and } \\
\text { Learning }\end{array}$ & $\begin{array}{c}\text { Monitoring } \\
\text { and } \\
\text { Evaluation } \\
\text { Systems }\end{array}$ \\
\hline $\begin{array}{l}\text { Service } \\
\text { Delivery }\end{array}$ & $\begin{array}{l}\text { Pearson } \\
\text { Correlation } \\
\text { Sig. (2-tailed) } \\
\text { N }\end{array}$ & 72 & & & & \\
\hline $\begin{array}{l}\text { Performance } \\
\text { Monitoring }\end{array}$ & $\begin{array}{l}\text { Pearson } \\
\text { Correlation } \\
\text { Sig. (2-tailed) } \\
\text { N }\end{array}$ & $\begin{array}{c}.808^{* *} \\
.010 \\
72\end{array}$ & 72 & & & \\
\hline $\begin{array}{l}\text { Measuring } \\
\text { Results }\end{array}$ & $\begin{array}{l}\text { Pearson } \\
\text { Correlation } \\
\text { Sig. (2-tailed) } \\
\text { N }\end{array}$ & $\begin{array}{c}.610^{* *} \\
.000 \\
72\end{array}$ & $\begin{array}{c}.710^{* *} \\
.000 \\
72\end{array}$ & 72 & $\begin{array}{c}.000 \\
72\end{array}$ & \\
\hline $\begin{array}{l}\text { Reporting } \\
\text { and } \\
\text { Learning }\end{array}$ & $\begin{array}{l}\text { Pearson } \\
\text { Correlation } \\
\text { Sig. (2-tailed) } \\
\text { N }\end{array}$ & $\begin{array}{c}.000 \\
72\end{array}$ & $\begin{array}{c}.703^{* *} \\
.000 \\
72\end{array}$ & $\begin{array}{c}.699^{* *} \\
.000 \\
72\end{array}$ & 72 & \\
\hline $\begin{array}{l}\text { Monitoring } \\
\text { and } \\
\text { Evaluation } \\
\text { Systems }\end{array}$ & $\begin{array}{l}\text { Pearson } \\
\text { Correlation } \\
\text { Sig. (2-tailed) } \\
\text { N }\end{array}$ & $\begin{array}{c}.001 \\
72\end{array}$ & $\begin{array}{c}.000 \\
72\end{array}$ & $\begin{array}{c}.691^{* *} \\
.000 \\
72\end{array}$ & $\begin{array}{c}.682^{* *} \\
.000 \\
72\end{array}$ & 72 \\
\hline
\end{tabular}


**. Correlation is significant at the 0.01 level (2-tailed)

Huber (2004) states that in the interpretation of results for the linear relationships in the study, for a weak correlation, " $r$ " ranges from \pm 0.10 to \pm 0.29 ; in a moderate correlation, " $r$ " ranges between \pm 0.30 and \pm 0.49 ; while in a strong correlation, " $r$ " ranges from \pm 0.5 and \pm 0.9 . The findings established that performance monitoring had a Pearson correlation of 0.808 an indication of a strong correlation with service delivery and a $\mathrm{p}$ value of $0.010<0.05$ an indication that the variable had a positive influence on service delivery. Measuring results had a Pearson correlation of 0.610 an indication of strong correlation with the service delivery and $p$ value of $0.00<0.05$. The study further established that reporting and learning had a Pearson correlation of 0.744 an indication that the variable had a strong correlation with service delivery and had a $\mathrm{p}$ value of $0.000<0.05$ an indication that the variable had a significant influence on service delivery. The study further pointed out that monitoring and evaluation systems had a Pearson correlation of 0.781 an indication of strong positive influence on service delivery and a $\mathrm{p}$ value of $0.001<0.05$ an indication that the variable significantly influenced service delivery. The study conducted regression analysis in order to establish the influence of devolution monitoring and evaluation on service delivery in Garissa County Government. The finding of model analysis, ANOVA and coefficient regression are indicated in the subsequent sections.

The coefficient of correlation $\mathrm{R}$ and coefficient of determination $\mathrm{R}^{2}$ are indicate in the Table 2 .

Table 2: Model Summary

\begin{tabular}{lllll}
\hline Model & R & R Square & Adjusted R Square & Std. Error of the Estimate \\
\hline 1 & $.817^{\mathrm{a}}$ & .668 & .663 & 1.19346 \\
\hline
\end{tabular}

a. Predictors: (Constant), Performance monitoring, Measuring results, Reporting and learning, Monitoring and evaluation systems

From the findings, coefficients of correlation $\mathrm{R}$ was 0.817 , an indication of strong positive correlation between variables, coefficient of adjusted determination $\mathrm{R}^{2}$ is 0.663 which translates to $66.3 \%$. This mean that $66.3 \%$ variations in dependent variables can be traced by; Performance monitoring, Measuring results, Reporting and learning, Monitoring and evaluation systems. The residual of $33.7 \%$ can be explained by other factors beyond the scope of the current study. An ANOVA was carried out at 5\% level of significance. A comparison between $\mathrm{F}$ calculated and $\mathrm{F}$ Critical was carried out. The findings are indicated in the Table 4.9.

Table 3: ANOVA

\begin{tabular}{llllll}
\hline Model & Sum of Squares & df & Mean Square & F & Sig. \\
\hline Regression & 1167.461 & 4 & 291.865 & 18.052 & $.000^{\mathrm{b}}$ \\
Residual & 1083.229 & 67 & 16.168 & & \\
Total & 2250.690 & 71 & & & \\
\hline
\end{tabular}

a. Dependent Variable: Service Delivery

b. Predictors: (Constant), Performance monitoring, Measuring results, Reporting and learning, Monitoring and evaluation systems

From the findings, $\mathrm{F}$ Calculated was 18.052 and $\mathrm{F}$ Critical was 2.501 an indication that $\mathrm{F}$ Calculated $>\mathrm{F}$ Critical indicating that the overall regression model was significant in the study. The $\mathrm{p}$ value $=$ $0.00<0.05$ an indication that at least one variable significantly influenced devolution monitoring and evaluation on service delivery in Garissa County Government. 
To determine the individual factor influencing service delivery in Garissa County Government, the following coefficient of regression were generated.

Table 4: Regression Coefficient

\begin{tabular}{llllll}
\hline & \multicolumn{2}{l}{$\begin{array}{l}\text { Unstandardized } \\
\text { Coefficients }\end{array}$} & \multicolumn{2}{l}{$\begin{array}{l}\text { Standardized } \\
\text { Coefficients }\end{array}$} & \\
\cline { 2 - 5 } Model & $\mathbf{B}$ & Std. Error & Beta & T & Sig. \\
\hline (Constant) & 1.377 & 4.140 & & .333 & .742 \\
Performance Monitoring & .700 & .180 & .346 & 3.895 & .001 \\
Measuring Results & .416 & .169 & .189 & 2.461 & .007 \\
Reporting and Learning & .496 & .156 & .430 & 3.174 & .004 \\
Monitoring and Evaluation Systems & .680 & .159 & .373 & 4.291 & .000 \\
\hline
\end{tabular}

a. Dependent Variable: Service Delivery

The resultant equation becomes:

$Y=1.377+0.700+\mathbf{0 . 4 1 6}_{2}+\mathbf{0 . 4 9 6}_{3}+\mathbf{0 . 6 8 0}_{4}$ Where: $Y=$ Service Delivery, $\mathrm{X}_{1}=$ Performance Monitoring, $\mathrm{X}_{2}=$ Measuring Results, $\mathrm{X}_{3}=$ Reporting and Learning and $\mathrm{X}_{4}=$ Monitoring and Evaluation Systems. From the findings, when all the variables were held constant, service delivery in Garissa County Government would be at 1.377. A unit increase in performance monitoring when all the other factors were held constant, service delivery would be at 0.700 . A unit increase in measuring results when all the other variables were held constant, service delivery would be at 0.416 . A unit increase in reporting and learning when all the factors were held constant, service delivery would be at 0.496 and a unit increase in monitoring and evaluation systems when all the other factors were held constant, service delivery at Garissa County Government would be at 0.680 . The study established that the $\mathrm{p}$ value of performance monitoring was $0.001<0.05$ an indication that performance monitoring had a positive influence in service delivery at Garissa County Government. The study is supported by Phiri (2015) who showed that performance monitoring, financing and stakeholder's analysis influences project completion positively. Similarly, Mugo (2014) revealed that the performance of the development projects was positively related to performance monitoring.

The $\mathrm{p}$ value of measuring results was $0.007<0.05$ an indication that the variable significantly influenced service delivery at Garissa county government. This agrees with Leuzzi (2013) who established that the as the project progresses, use of M\&E project results keep stakeholders aware of the current state of affairs and it keeps the project team on top of project tasks and use of $M \& E$ project results enhances Project Delivery Capability thereby increasing the success rate of a project. The $\mathrm{p}$ value of reporting and learning was $0.004<0.05$, this implies that reporting and learning had a significant influence on service delivery at Garissa county government. This is supported by Wang and Gibson (2008) who established that pre-project monitoring and evaluation design and systems had a positive and significant relationship with the success of the projects and projects with better pre-project planning are more likely to have a better project performance at completion. The study established that monitoring and evaluation systems had a $\mathrm{p}$ value of $0.000<0.05$ an indication that the variable significantly influenced service delivery at Garissa county government. Wang and Gibson (2008) who established that pre-project monitoring and evaluation design and systems had a positive and significant relationship with the success of the projects and projects with better pre-project planning are more likely to have a better project performance at completion. 


\section{CONCLUSION}

The study concludes that the county government of Garissa performed evaluation of cost performance. The county government evaluated whether projects in the county were of highquality performance. The county government carried an evaluation of financial performance of the county. The county government of Garissa evaluated whether county projects were delivered on time as supposed to. The study concludes that the county government conducted Feasibility tests before projects implementation. The county government conducted surveys to establish the durability of projects. The county government established the sustainability of Projects before implementation. Garissa County tested whether county projects were compatible before embarking on them. The study concludes that the county government of Garissa established an understandable mode of reporting for $\mathrm{M} \& \mathrm{E}$ results. The county government established flexible feedback mechanisms for monitoring and evaluation results. Garissa county government established the frequency of reporting monitoring and evaluation information. Garissa county government established effective communication plans for $\mathrm{M} \& \mathrm{E}$ information. The study further concludes that the county government aligned organizational structure with $\mathrm{M} \& \mathrm{E}$ systems for comprehensive results. The county government had developed $\mathrm{M} \& \mathrm{E}$ databases for data storage and follow ups. The county government of Garissa had up to date routine monitoring systems for effective $M \&$ E process. The county government of Garissa had up to date appraisal systems for effective $\mathrm{M} \& \mathrm{E}$ process.

\section{RECOMMENDATIONS}

The study recommends that the county government of Garissa ought to performed evaluation of cost performance. The county government ought to evaluate whether projects in the county were of high-quality performance. The county government ought to carry an evaluation of financial performance of the county. The county government of Garissa ought to evaluate whether county projects were delivered on time as supposed to. The study recommends that the county government of Garissa ought to conduct feasibility tests before projects implementation. The county government ought to conduct surveys to establish the durability of projects. The county government ought to establish the sustainability of Projects before implementation. Garissa County ought to test whether county projects were compatible before embarking on them. The study recommends that the county government of Garissa ought to establish an understandable mode of reporting for $\mathrm{M} \& \mathrm{E}$ results. The county government ought to establish flexible feedback mechanisms for monitoring and evaluation results. Garissa county government ought to establish the frequency of reporting monitoring and evaluation information. Garissa county government ought to establish effective communication plans for $\mathrm{M} \& \mathrm{E}$ information. The study recommends that the county government ought to align organizational structure with $\mathrm{M} \& \mathrm{E}$ systems for comprehensive results. The county government ought to developed M \& E databases for data storage and follow ups. The county government of Garissa ought to have an up to date routine monitoring systems for effective $M \& E$ process. The county government of Garissa ought to have up to date appraisal systems for effective $M \&$ E process.

\section{REFERENCES}

Allen, K.\&Chudley, L. (2013); Effectively planning Ux design projects.http:// uxdesign.smashingmagazine.com. 
Estrella, M. (ED.), Blauert, J., Campilan, D., Gaventa, J., Gonsalves, J., Guijt, I., Johnson, D., Ricafort, R. (2000): Learning from change: issues and experiences in participatory monitoring and evaluation. Intermediate Technologies Publications, London, UK.274 p.

Guijt, I. and J. Gaventa. (2011). Participatory Monitoring and Evaluation: Learning from Change. IDS Policy Briefing 12. Brighton: Institute of Development Studies.

Hacking T,\& Guthrie P (2006) Sustainable development objectives in impact assessment: why are they needed and where do they come from? J Environ Assess Policy Manage $8(3): 341-371$

Hatch, M. (2013). Resource Requirements and Environmental Dependency. European Scientific Journal, August 2013 edition Vol.12.

International Fund for Agricultural Development [IFAD]. (2002). A Guide for Project M\&E. IFAD, Rome.

John, W. (2007). Effects of Resource Allocation Policies for Reducing Project Durations: A Systems Modelling Approach Princeton. USA: New Jersey

Kahilu, D. (2010). Monitoring and evaluation report of "the impact of information and communication technology service (ICTs) among end users in the ministry of agriculture and cooperatives in Zambia. Journal of Development and Agricultural Economics, 3(7):302-311

Leuzzi, N. (2013). Logical framework approach to development in Ghana.

Mackay, P. (2007). "How to Build Monitoring and Evaluation Systems to Support Better Government," Washington DC: World Bank, 2007.

Miles, S. (2013). Stakeholders: essentially contested or just confused? Journal of Business Ethics 108 (3): 285-298.

Mugo, P. M. (2014). Monitoring and Evaluation of Development Projects and Economic Policy Development in Kenya (Doctoral dissertation, School of Economics, University of Nairobi).

Pfeiffer, W., \& Salancil, R. (1978). Resource Dependency Theory. Macmillan publishers. United Kingdom.

Phiri, B. (2015). Influence of monitoring and evaluation on project performance: A Case of African Virtual University, Kenya. University of Nairobi.

Rogito, D. O. (2010). Influence of monitoring and evaluation on project's performance: case of Youth Enterprise Development Fund in Marani district, Kenya (Doctoral dissertation, University of Nairobi, Kenya).

Roselyne, S. (2016). Influence of monitoring and evaluation tools on projects performance of building and construction projects in Kenyan public universities: A case of the University of Nairobi.

United Nations Development Programme Evaluation Office. (2002). Handbook on Monitoring and Evaluating for Results. New York: United Nations Development Program. 
Van de Kerkhof M \& Wieczorek A (2005) Learning and stakeholder participation in transition processes towards sustainability: methodological considerations. Technol Forecast Soc Change 72:733-747.

Wang, T. \& Gibson, K. (2008). A study of pre-project planning and project success using Ann and regression models.

World Bank (2002). Monitoring \& Evaluation: some tools, methods and approaches. The World Bank, Washington, D.C.

This is an open-access article published and distributed under the terms and conditions of the ${ }_{(\mathrm{oc}) \text { EY }}$ Creative Commons Attribution 4.0 International License of United States unless otherwise stated. Access, citation and distribution of this article is allowed with full recognition of the authors and the source.

Authors seeking to publish with an International Peer Reviewed Journal should consider www.ijcab.org by writing to the Editor at editor@ijcab.org. List of our Journals are Available at www.ijcab.org/journals 